\title{
THE COMPARATIVE STUDY OF CCD AND MCCD IN THE PRESENCE OF A MISSING DESIGN POINT
}

Jaja E.I., Iwundu M.P. and Etuk E.H.

Department of Mathematics/Science, Rivers State University, Port Harcourt

Department of Mathematics/Science, University of Port Harcourt.

Cite this article:

Jaja E.I., Iwundu M.P., Etuk E.H. (2021), The Comparative Study of CCD and MCCD in the Presence of a Missing Design Point. African Journal of Mathematics and Statistics Studies 4(2), 10-24. DOI: 10.52589/AJMSS-

JF1A1DZA.

\section{Manuscript History}

Received: 13 April 2021

Accepted: 30 April 2021

Published: 11 May 2021

Copyright $\odot 2020$ The Author(s).

This is an Open Access article distributed under the terms of Creative Commons AttributionNonCommercial-NoDerivatives 4.0 International (CC BY-NC-ND 4.0 ), which permits anyone to share, use, reproduce and redistribute in any medium, provided the original author and source are credited.
ABSTRACT: The work constructed a modified central composite design from a rotatable central composite design augmented with seven center points adapted from the work of Wu and $\mathrm{Li}$ (2002). The comparison of the robustness of the CCD and MCCD to missing observation was investigated at various design points of factorial, axial and center points' when the model is non-standard, using A-efficiency and the Losses associated. The results of the evaluations of the designs to missing observations are presented, and the MCCD is shown to be more A-optimal while the CCD is more robust and relatively A-efficient to a missing observation.

KEYWORDS: Missing Observations, A -optimality, CCD, MCCD 


\section{INTRODUCTION}

Many experimenters are saddled with the investigation of fitting the input and output relationship in an experiment, when some observations of the experimental unit may not be available due to unexplainable situations. These unexplainable situations may occur due to a number of reasons, which may include, but not limited to natural causes, man-made causes or machine error, etc. These may result in missing observations or incomplete data; Subramani (2004) and Ahmed L. A. (2016) calls it non-orthogonal data. Missing observations could grossly affect the statistical power of a test. Several methods had been proposed to handle missing observations in a project, these include substitution, the use of robust statistics, robust design methods etc. (Wallin 2009; Iwundu 2017).

This study is focused on how experimental design may be robust when an observation is missing using the concept of A-efficiency and the loss principle therefrom. The literatures on robustness in missing observations are replete, these can be seen in the works of Akhtar and Prescott (1986) that applied the minimax loss criterion in the evaluation and generation of CCDs, which was further used to generate 26 runs on the four factor classical CCDs. Taguchi et. al (2000) opines that robust designs enable engineers to efficiently gather technological information required to produce high quality, low-cost products, when some observations are not in place. Gremyr (2005) used the term robust design methodology (RDM) to mean the systematic efforts to achieve insensitivity to noise factors when some observations are missing. Furthermore, the effect of missing observations on predictive capability of central composite design was studied by Yakubu et.al. (2014). They concluded that the precision of the model estimates and design prediction properties were adversely affected when an observation is missing. Smucker et. al (2017) opine that optimal designs fared better than classical designs in terms of robustness when some design points are missing. Alrweili et. al (2019) worked on the 'robustness of response surface designs to missing data' where minimax loss response surface designs are constructed, which turned out to be more robust than the original designs,

The identification and removal of one or more observations in a design measure, which may not effectively contribute to the performance of a project was handled extensively in the work of Iwundu (2017) with the help of the Hat Matrix. Akram (2002) also utilized the hat matrix to study the robustness of CCDs when some observations are missing.

Rotatability in designs as a concept was introduced by Box and Hunter (1957), and its unique property is that the variances estimate of the response are at points equidistant from the center of the design. Das and Narasimham (1962) constructed a rotatable design from a Balance incomplete block design (BIBD).

Experimental models are the heartbeat of every project, as they help the researcher to extract experimental data for analysis and such a model is always assumed prior to the commencement of an experiment. Therefore, this study opted for the second-order non-standard polynomial model, but in practice the second-order standard polynomial model is the most preferred model in most projects, however, not all the terms in the standard second-order model maybe statistically significant, resulting in the removal of some parameter of a standard model. The model that is generated as a result of the removal of some parameters in a standard model is called a non-standard model (Myers et. al 2009; Iwundu 2018; Iwundu and Jaja 2017; Alrweili et. al 2019). 
The general form of a second-order response surface model is normally presented as

$$
y=a_{0}+\sum_{i=1}^{k} a_{i} x_{i}+\sum_{i=1}^{k-1} \sum_{j=i+1}^{k} a_{i j} x_{i} x_{j}+\sum_{i=1}^{k} a_{i i} x_{i}^{2}+\xi
$$

Where $y$ is the response surface and $x_{i}$ are the input variables and $a_{0}, a_{i}$ are the linear regression parameters while ${ }^{a_{i j}}$ are the interaction parameters, ${ }^{a_{i i}}$ are the quadratic parameters and $\xi_{\text {is }}$ the stochastic error term. Furthermore, the second-order model is normally used to fit a central composite design (CCD), which was introduced by Box and Wilson (1951). Now for a kfactorial central composite design is composed of full or fractional factorial design $\left(2^{k}\right.$ or $2^{k-p}$ ) coded as +1 and -1 , axial portion made up of $2 k$ points, such that each coordinate axis has two points $\alpha$ at a distance from the design center and $n_{c}$ center point at the origin of the design. The total number of design points associated with a CCD is $n=n_{f}+n_{a}+n_{c}$

The analysis of this study is done with the aid of the A-optimality criterion. Smucker et. al (2017) opine that the A-optimality criterion is used to minimize the average prediction variance across a design surface, which is a way of assessing the design capability to estimate the underlying model. The A-optimality minimizes the trace of the covariance matrix; an Aoptimal criterion is that which

$$
\min \zeta \operatorname{trace}\left(X^{T} X\right)^{-1}
$$

This work will build a modified central composite design from the rotatable central composite design with the aid of the leveraging capability of the hat-matrix. The primary aim of this study is to use the A-efficiency and its loss principle to compare the performance of the central composite design and the modified central composite design when an observation is missing.

\section{MATERIALS AND METHODS}

Consider a second order non-linear response surface model in $\mathrm{k}$ variables and $\mathrm{n}$ design points shown in equation 1.1 above, which may be expressed as:

$$
Y=X A+\xi
$$

Where $\underline{Y}$ is the $n \times 1$ response vector, $\mathrm{X}$ is the $n \times p$ model matrix, A is the $p \times 1$ vector of

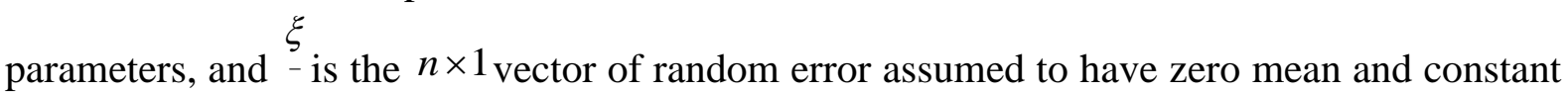
variance $\sigma^{2}$.

Based on the regression model in eqn 2.1 the standard least square estimate of the parameter A is given as

$$
\underline{\hat{A}}=\left(X^{T} X\right) X^{T} \underline{y}
$$


Such that the fitted model of the response variable $\underline{Y}$ is

$\underline{\hat{Y}}=X \underline{\hat{A}}=X\left(X^{T} X\right) X^{T} y=H y$

This is used to estimate the response variable at any point in the design region. Where $H=\left\{h_{i j}\right\}$ is the hat matrix and its diagonal elements are the leverage values of the design with the property that trace value of the hat matrix is the number of the model parameters.

The A- optimality is geared to improve the precision of the estimates of the model parameters by minimizing the trace of the variance-covariance matrix. This is expressed in the form

$$
\min _{\zeta} \operatorname{trace}\left(X^{T} X\right)^{-1}
$$

in the presence of any missing observations, the response vector and the model matrix are partitioned as presented below:

$$
\left[\begin{array}{c}
\underline{Y}_{m} \\
\ldots \\
\underline{Y}_{r}
\end{array}\right] \text { and }\left[\begin{array}{l}
\underline{X}_{m} \\
\ldots \\
\underline{X}_{r}
\end{array}\right]
$$

Where $\underline{X}_{m}$ are the missing observations and $\underline{X}_{r}$ are the remaining observations, the complete information matrix is expressed as follows:

$$
X^{T} X=X_{m}^{T} X_{m}+X_{r}^{T} X_{r}
$$

Now the ordinary least square estimator of the remaining data points in the design is

$$
\underline{\hat{A}}_{r}^{*}=\left(X_{r}^{T} X_{r}\right) X_{r}^{T} \underline{y_{r}}
$$

The variance of the estimator is

$$
\operatorname{var}\left(\underline{\hat{A}}_{r}^{*}\right)=\left(X_{r}^{T} X_{r}\right)^{-1}
$$

The A-optimality minimizes the variance of the parameter estimate with a view to increase the precision of the parameter, but whenever some observations are missing, the variance is increased that makes it less precise as a result the differential increase in variance given by

$$
d . v=\operatorname{trace}\left(X_{r}^{T} X_{r}\right)^{-1}-\operatorname{trace}\left(X^{T} X\right)^{-1}
$$

The efficiency of the design with respect to the missing observation is

$$
A_{\text {eff }}=\frac{\operatorname{trace}\left(X^{T} X\right)^{-1}}{\operatorname{trace}\left(X_{r}^{T} X_{r}\right)^{-1}}
$$


The relative loss in A-optimality measures the amount of reduction in the precision of the parameter estimates when some observations are missing and is given as

$$
R L=1-\frac{\operatorname{trace}\left(X^{T} X\right)}{\operatorname{trace}\left(X_{r}^{T} X_{r}\right)}
$$

This expression is used to estimate the relative loss incurred when some observations are missing in the designs.

\section{RESULTS}

This work is based on the real-life data culled from the work of $\mathrm{Wu}$ and $\mathrm{Li}$ (2002) for the impregnating and dying on the mechanical properties of a $\mathrm{PCOMo} / \mathrm{Al}_{2} \mathrm{O}_{3}$ (solution of ammonium heptamolybdate, cobalt nitrate and phosphoric acid) hydrotreating catalyst. The support was commercial $\gamma-\mathrm{Al}_{2} \mathrm{O}_{3}$ (3.82mm cylindrical extrudates). The experiment was carried out by the techniques of co-impregnating using a pore filling method. After drying at $200^{\circ} \mathrm{C}$ for $3 \mathrm{~h}, 30 \mathrm{~g}$ of support was co-impregnated with $60 \mathrm{ml}$ of a mixed aqueous solution of ammonium heptamolybdate, cobalt nitrite and phosphoric acid, which was left at room temperature for $2 \mathrm{~h}$. The drying in air was carried out in a drying cupboard, with putting in the samples after temperature reached the present value.

Table 3.1: Experimental range and levels of the factors

\begin{tabular}{llllllll}
\hline Factors & Units & Notations & \multicolumn{6}{c}{ Range and levels } \\
\cline { 5 - 9 } & & $T_{i}$ & 20 & 35 & 50 & 65 & 80 \\
\hline Impregnating & ${ }^{0} \mathrm{C}$ & $t_{i}$ & 4 & 6 & 8 & 10 & 12 \\
temperature & & $T_{d}$ & 100 & 125 & 150 & 175 & 200 \\
Impregnating time & $\mathrm{H}$ & $t_{d}$ & 4 & 6 & 8 & 10 & 12 \\
Drying temperature & ${ }^{0} \mathrm{C}$ & $\mathrm{H}$ & & &
\end{tabular}

\section{Design}

The controlling factors are the four variables of Impregnating temperature, Impregnating time, Drying temperature and Drying time shown in table 3.1 above with their experimental ranges and levels where the higher and lower limits of each factor were coded at -2 and +2 respectively. A four factors rotatable central composite design with seven center points consisting of 31 experimental runs was implored.

Now the fifteen parameter second-order standard model was used to model the results as presented below the interest of this research is the first response represented by $\left(0, g / \mathrm{cm}^{3}\right)$ : 


$$
\begin{aligned}
& y=\beta_{0}+\beta_{1} x_{1}+\beta_{2} x_{2}+\beta_{3} x_{3}+\beta_{4} x_{4}+\beta_{12} x_{12}+\beta_{13} x_{13}+\beta_{14} x_{4} \\
& +\beta_{23} x_{23}+\beta_{24} x_{24}+\beta_{34} x_{34}+\beta_{11} x_{11}^{2}+\beta_{22} x_{22}^{2}+\beta_{33} x_{33}^{2}+\beta_{44} x_{44}^{2}+\xi
\end{aligned}
$$

Table 3.2: Central Composite Rotatable Design and Experimental Results Central

\begin{tabular}{|c|c|c|c|c|c|c|c|}
\hline \multirow[t]{2}{*}{ No. } & \multicolumn{4}{|c|}{ Central composite design } & \multicolumn{3}{|c|}{ Experimental results } \\
\hline & $x_{1}$ & $x_{2}$ & $x_{3}$ & $x_{3}$ & $o, \mathrm{~g} / \mathrm{cm}^{3}$ & $\bar{L}, N$ & $m$ \\
\hline 1 & -1 & -1 & -1 & -1 & 1.72 & 24.9 & 4.63 \\
\hline 2 & -1 & -1 & -1 & 1 & 1.78 & 26.5 & 3.74 \\
\hline 3 & -1 & -1 & 1 & -1 & 1.70 & 39.2 & 4.53 \\
\hline 4 & -1 & -1 & 1 & 1 & 1.72 & 40.6 & 4.14 \\
\hline 5 & -1 & 1 & -1 & -1 & 1.82 & 37.3 & 4.32 \\
\hline 6 & -1 & 1 & -1 & 1 & 1.83 & 41.0 & 3.28 \\
\hline 7 & -1 & 1 & 1 & -1 & 1.74 & 33.6 & 4.89 \\
\hline 8 & -1 & 1 & 1 & 1 & 1.79 & 35.3 & 3.60 \\
\hline 9 & 1 & -1 & -1 & -1 & 1.78 & 30.0 & 2.77 \\
\hline 10 & 1 & -1 & -1 & 1 & 1.81 & 35.0 & 2.79 \\
\hline 11 & 1 & -1 & 1 & -1 & 1.71 & 35.2 & 3.33 \\
\hline 12 & 1 & -1 & 1 & 1 & 1.74 & 34.5 & 3.55 \\
\hline 13 & 1 & 1 & -1 & -1 & 1.78 & 36.1 & 3.61 \\
\hline 14 & 1 & 1 & -1 & 1 & 1.86 & 36.6 & 2.86 \\
\hline 15 & 1 & 1 & 1 & -1 & 1.74 & 34.0 & 3.53 \\
\hline 16 & 1 & 1 & 1 & 1 & 1.72 & 35.2 & 3.32 \\
\hline 17 & -2 & 0 & 0 & 0 & 1.70 & 33.7 & 5.01 \\
\hline 18 & 2 & 0 & 0 & 0 & 1.78 & 28.3 & 3.76 \\
\hline 19 & 0 & -2 & 0 & 0 & 1.76 & 38.6 & 3.53 \\
\hline 20 & 0 & 2 & 0 & 0 & 1.87 & 40.1 & 4.17 \\
\hline 21 & 0 & 0 & -2 & 0 & 1.82 & 36.6 & 4.04 \\
\hline 22 & 0 & 0 & 2 & 0 & 1.74 & 43.6 & 3.59 \\
\hline 23 & 0 & 0 & 0 & -2 & 1.77 & 33.5 & 3.70 \\
\hline 24 & 0 & 0 & 0 & 2 & 1.76 & 31.8 & 3.28 \\
\hline 25 & 0 & 0 & 0 & 0 & 1.70 & 32.3 & 3.66 \\
\hline 26 & 0 & 0 & 0 & 0 & 1.72 & 30.9 & 3.37 \\
\hline 27 & 0 & 0 & 0 & 0 & 1.79 & 31.4 & 3.60 \\
\hline 28 & 0 & 0 & 0 & 0 & 1.76 & 29.1 & 4.07 \\
\hline 29 & 0 & 0 & 0 & 0 & 1.77 & 28.2 & 3.63 \\
\hline 30 & 0 & 0 & 0 & 0 & 1.75 & 28.4 & 3.98 \\
\hline 31 & 0 & 0 & 0 & 0 & 1.77 & 33.5 & 3.63 \\
\hline
\end{tabular}
rotatable design and 


\section{Model Selection Method, Design Matrix and Hat Matrix}

From the above real life data a stepwise backward elimination procedure was applied and a posterior regression model was generated based on the following statistics obtained from mini tab 16 with R-Sq(adj) 63.30, Mallows Cp 4.7, S-0.0282,R-sq 73.09 only for the first response y1. The non-standard model generated with a few of the parameters dropped is as follows:

$$
y_{1}=1.744+0.0083 x_{1}+0.0225 x_{2}-0.0283 x_{3}+0.01 x_{4}-0.0125 x_{1} x_{2}-0.0075 x_{1} x_{3}+0.0162 x_{2}^{2}+.0075 x_{3}^{2}+\xi
$$

The above model is further represented as follows:

$$
y_{1}=\beta_{0}+\beta_{1} x_{1}+\beta_{2} x_{2}+\beta_{3} x_{3}+\beta_{4} x_{4}+\beta_{12} x_{1} x_{2}+\beta_{13} x_{1} x_{3}+\beta_{22} x_{2}^{2}+. \beta_{33} x_{3}^{2}+\xi
$$

The design matrix linked to the selected model and the design is a $31 \times 9$ matrix shown below:

$X=\left[\begin{array}{lllllllll}1 & -1 & -1 & -1 & -1 & 1 & 1 & 1 & 1 \\ 1 & 1 & -1 & -1 & -1 & -1 & -1 & 1 & 1 \\ 1 & -1 & 1 & -1 & -1 & -1 & 1 & 1 & 1 \\ 1 & 1 & 1 & -1 & -1 & 1 & -1 & 1 & 1 \\ 1 & -1 & -1 & 1 & -1 & 1 & -1 & 1 & 1 \\ 1 & 1 & -1 & 1 & -1 & -1 & 1 & 1 & 1 \\ 1 & -1 & 1 & 1 & -1 & -1 & -1 & 1 & 1 \\ 1 & 1 & 1 & 1 & -1 & 1 & 1 & 1 & 1 \\ 1 & -1 & -1 & -1 & 1 & 1 & 1 & 1 & 1 \\ 1 & 1 & -1 & -1 & 1 & -1 & -1 & 1 & 1 \\ 1 & -1 & 1 & -1 & 1 & -1 & 1 & 1 & 1 \\ 1 & 1 & 1 & -1 & 1 & 1 & -1 & 1 & 1 \\ 1 & -1 & -1 & 1 & 1 & 1 & -1 & 1 & 1 \\ 1 & 1 & -1 & 1 & 1 & -1 & 1 & 1 & 1 \\ 1 & -1 & 1 & 1 & 1 & -1 & -1 & 1 & 1 \\ 1 & 1 & 1 & 1 & 1 & 1 & 1 & 1 & 1 \\ 1 & 2 & 0 & 0 & 0 & 0 & 0 & 0 & 0 \\ 1 & -2 & 0 & 0 & 0 & 0 & 0 & 0 & 0 \\ 1 & 0 & 2 & 0 & 0 & 0 & 0 & 4 & 0 \\ 1 & 0 & -2 & 0 & 0 & 0 & 0 & 4 & 0 \\ 1 & 0 & 0 & 2 & 0 & 0 & 0 & 0 & 4 \\ 1 & 0 & 0 & -2 & 0 & 0 & 0 & 0 & 4 \\ 1 & 0 & 0 & 0 & 2 & 0 & 0 & 0 & 0 \\ 1 & 0 & 0 & 0 & -2 & 0 & 0 & 0 & 0 \\ 1 & 0 & 0 & 0 & 0 & 0 & 0 & 0 & 0 \\ 1 & 0 & 0 & 0 & 0 & 0 & 0 & 0 & 0 \\ 1 & 0 & 0 & 0 & 0 & 0 & 0 & 0 & 0 \\ 1 & 0 & 0 & 0 & 0 & 0 & 0 & 0 & 0 \\ 1 & 0 & 0 & 0 & 0 & 0 & 0 & 0 & 0 \\ 1 & 0 & 0 & 0 & 0 & 0 & 0 & 0 & 0 \\ 1 & 0 & 0 & 0 & 0 & 0 & 0 & 0 & 0\end{array}\right]$


The information matrix $X^{T} X$ is

$$
X^{T} X=\left[\begin{array}{rrrrrrrrr}
31 & 0 & 0 & 0 & 0 & 0 & 0 & 24 & 24 \\
0 & 24 & 0 & 0 & 0 & 0 & 0 & 0 & 0 \\
0 & 0 & 24 & 0 & 0 & 0 & 0 & 0 & 0 \\
0 & 0 & 0 & 24 & 0 & 0 & 0 & 0 & 0 \\
0 & 0 & 0 & 0 & 24 & 0 & 0 & 0 & 0 \\
0 & 0 & 0 & 0 & 0 & 16 & 0 & 0 & 0 \\
0 & 0 & 0 & 0 & 0 & 0 & 16 & 0 & 0 \\
24 & 0 & 0 & 0 & 0 & 0 & 0 & 48 & 16 \\
24 & 0 & 0 & 0 & 0 & 0 & 0 & 16 & 48
\end{array}\right]
$$

The determinant of the information matrix is $2.2613 \mathrm{e}+012$

The normalized information matrix is $\frac{1}{N} X^{T} X$

$$
\frac{1}{N}\left(X^{T} X\right)=\left[\begin{array}{cccccccccc}
1.0000 & 0 & 0 & 0 & 0 & 0 & 0 & 0.7742 & 0.7742 \\
0 & 0.7742 & 0 & 0 & 0 & 0 & 0 & 0 & 0 \\
0 & 0 & 0.7742 & 0 & 0 & 0 & 0 & 0 & 0 \\
0 & 0 & 0 & 0.7742 & 0 & 0 & 0 & 0 & 0 \\
0 & 0 & 0 & 0 & 0.7742 & 0 & 0 & 0 & 0 \\
0 & 0 & 0 & 0 & 0 & 0.5161 & 0 & 0 & 0 \\
0 & 0 & 0 & 0 & 0 & 0 & 0.5161 & 0 & 0 \\
0.7742 & 0 & 0 & 0 & 0 & 0 & 0 & 1.5484 & 0.5161 \\
0.7742 & 0 & 0 & 0 & 0 & 0 & 0 & 0.5161 & 1.5484
\end{array}\right]
$$

The determinant of the normalized information matrix is 0.0855

The associated hat matrix $H=X\left(X^{T} X\right)^{-1} X^{T}$ is as presented below:
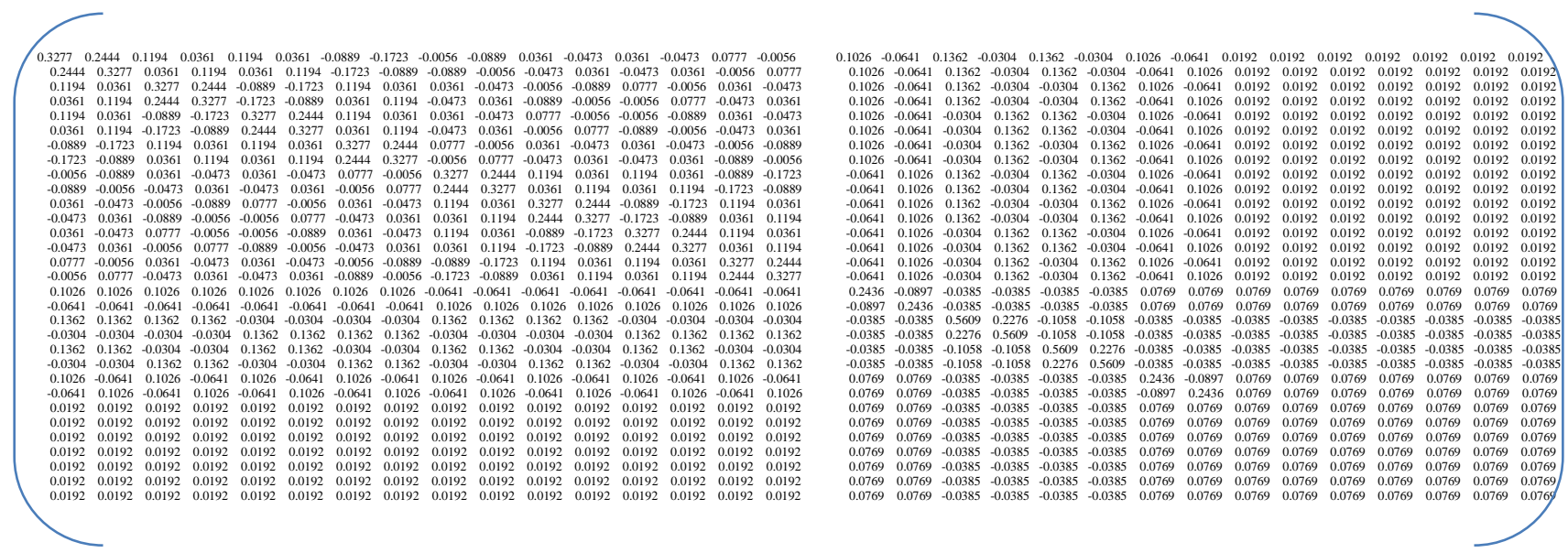
The above hat matrix showed constant diagonal values at the factorial at 0.3277 as well as at the center points 0.0769 respectively, while the axial distances have two distinct values of 0.2436 and 0.5609 , which indicates that the coordinates with the higher values contributes more while the ones with the lower values are less influential and therefore are removed. The reduced $\mathrm{CCD}$ as presented below will be without the following axial coordinates $( \pm 2,0,0,0)$ and $(0,0,0, \pm 2)$ all other components are as in the CCD. The new design i s a $27 \times 4$ modified central composite design MCCD

$\zeta_{M C C D}=\left[\begin{array}{llll}-1 & -1 & -1 & -1 \\ 1 & -1 & -1 & -1 \\ -1 & 1 & -1 & -1 \\ 1 & 1 & -1 & -1 \\ -1 & -1 & 1 & -1 \\ 1 & -1 & 1 & -1 \\ -1 & 1 & 1 & -1 \\ 1 & 1 & 1 & -1 \\ -1 & -1 & -1 & 1 \\ 1 & -1 & -1 & 1 \\ -1 & 1 & -1 & 1 \\ 1 & 1 & -1 & 1 \\ -1 & -1 & 1 & 1 \\ -1 & 1 & 1 & 1 \\ 1 & 1 & 1 & 1 \\ 0 & 2 & 0 & 0 \\ 0 & -2 & 0 & 0 \\ 0 & 0 & 2 & 0 \\ 0 & 0 & -2 & 0 \\ 0 & 0 & 0 & 0 \\ 0 & 0 & 0 & 0 \\ 0 & 0 & 0 & 0 \\ 0 & 0 & 0 & 0 \\ 0 & 0 & 0 & 0 \\ 0 & 0 & 0 & 0 \\ 0 & 0 & 0 & 0\end{array}\right]$ 
African Journal of Mathematics and Statistics Studies

ISSN: 2689-5323

Volume 4, Issue 2, 2021 (pp. 10-24)

The design matrix is built from the model and the design which is a $27 \times 9$ matrix as shown below:

$$
X_{M C C D}=\left[\begin{array}{lllllllll}
1 & -1 & -1 & -1 & -1 & 1 & 1 & 1 & 1 \\
1 & 1 & -1 & -1 & -1 & -1 & -1 & 1 & 1 \\
1 & -1 & 1 & -1 & -1 & -1 & 1 & 1 & 1 \\
1 & 1 & 1 & -1 & -1 & 1 & -1 & 1 & 1 \\
1 & -1 & -1 & 1 & -1 & 1 & -1 & 1 & 1 \\
1 & 1 & -1 & 1 & -1 & -1 & 1 & 1 & 1 \\
1 & -1 & 1 & 1 & -1 & -1 & -1 & 1 & 1 \\
1 & 1 & 1 & 1 & -1 & 1 & 1 & 1 & 1 \\
1 & -1 & -1 & -1 & 1 & 1 & 1 & 1 & 1 \\
1 & 1 & -1 & -1 & 1 & -1 & -1 & 1 & 1 \\
1 & -1 & 1 & -1 & 1 & -1 & 1 & 1 & 1 \\
1 & 1 & 1 & -1 & 1 & 1 & -1 & 1 & 1 \\
1 & -1 & -1 & 1 & 1 & 1 & -1 & 1 & 1 \\
1 & 1 & -1 & 1 & 1 & -1 & 1 & 1 & 1 \\
1 & -1 & 1 & 1 & 1 & -1 & -1 & 1 & 1 \\
1 & 0 & 2 & 0 & 0 & 0 & 0 & 4 & 0 \\
1 & 0 & -2 & 0 & 0 & 0 & 0 & 4 & 0 \\
1 & 0 & 0 & 2 & 0 & 0 & 0 & 0 & 4 \\
1 & 0 & 0 & 0 & 0 & 0 & 0 & 0 & 0 \\
1 & 0 & 0 & 0 & 0 & 0 & 0 & 0 & 0 \\
1 & 0 & 0 & 0 & 0 & 0 & 0 & 0 & 0 \\
1 & 0 & 0 & 0 & 0 & 0 & 0 & 0 & 0 \\
1 & 0 & 0 & 0 & 0 & 0 & 0 & 0 & 0 \\
1 & 0 & 0 & 0 & 0 & 0 & 0 & 0 & 0 \\
1 & 0 & 0 & 0 & 0 & 0 & 0 & 0 & 0
\end{array}\right]
$$

The information matrix of the MCCD is

$$
X^{T} X=\left[\begin{array}{ccccccccccc}
27 & 0 & 0 & 0 & 0 & 0 & 0 & 24 & 24 \\
0 & 16 & 0 & 0 & 0 & 0 & 0 & 0 & 0 \\
0 & 0 & 24 & 0 & 0 & 0 & 0 & 0 & 0 \\
0 & 0 & 0 & 24 & 0 & 0 & 0 & 0 & 0 \\
0 & 0 & 0 & 0 & 16 & 0 & 0 & 0 & 0 \\
0 & 0 & 0 & 0 & 0 & 16 & 0 & 0 & 0 \\
0 & 0 & 0 & 0 & 0 & 0 & 16 & 0 & 0 \\
24 & 0 & 0 & 0 & 0 & 0 & 0 & 48 & 16 \\
24 & 0 & 0 & 0 & 0 & 0 & 0 & 16 & 48
\end{array}\right]
$$

The determinant of the information matrix is $6.9578 \mathrm{e}+011$ 
The normalized information matrix for the MCCD is

$$
\frac{1}{27} X^{T} X=\left[\begin{array}{ccccccccc}
1.0000 & 0 & 0 & 0 & 0 & 0 & 0 & 0.8889 & 0.8889 \\
0 & 0.5926 & 0 & 0 & 0 & 0 & 0 & 0 & 0 \\
0 & 0 & 0.8889 & 0 & 0 & 0 & 0 & 0 & 0 \\
0 & 0 & 0 & 0.8889 & 0 & 0 & 0 & 0 & 0 \\
0 & 0 & 0 & 0 & 0.5926 & 0 & 0 & 0 & 0 \\
0 & 0 & 0 & 0 & 0 & 0.5926 & 0 & 0 & 0 \\
0 & 0 & 0 & 0 & 0 & 0 & 0.5926 & 0 & 0 \\
0.8889 & 0 & 0 & 0 & 0 & 0 & 0 & 1.7778 & 0.5926 \\
0.8889 & 0 & 0 & 0 & 0 & 0 & 0 & 0.5926 & 1.7778
\end{array}\right]
$$

Table 3.3: The optimality of CCD and MCCD with replicated center points for the nonstandard model.

\begin{tabular}{llll}
\hline Design & Design points & Determinant & a-opt \\
\hline CCD & 31 & $2.2613 \mathrm{e}+012$ & 0.4453 \\
MCCD & 27 & $6.9578 \mathrm{e}+011$ & 0.5226 \\
\hline
\end{tabular}

Optimality Values for CCD and MCCD When One Observation is Missing.

Table 3.4: CCD Optimality

\begin{tabular}{llll}
\hline Design type & Design points N & Det & A-opt \\
\hline Full & 31 & $2.2613 \mathrm{e}+012$ & 0.4453 \\
Factorial & 30 & $1.5202 \mathrm{e}+012$ & 0.4598 \\
Axial & 30 & $1.7105 \mathrm{e}+012$ & 0.4563 \\
Axial & 30 & $9.9294 \mathrm{e}+011$ & $0.4836^{*}$ \\
Center & 30 & $2.0874 \mathrm{e}+012$ & 0.4453 \\
\hline
\end{tabular}

Table 3.5: MCCD Optimality

\begin{tabular}{llll}
\hline Design type & Design points N & Det & A-opt \\
\hline Full & 27 & $6.9578 \mathrm{e}+011$ & 0.5226 \\
Factorial & 26 & $4.3728 \mathrm{e}+011$ & 0.5543 \\
Axial & 26 & $2.9957 \mathrm{e}+011$ & $0.5766^{*}$ \\
Center & 26 & $6.1848 \mathrm{e}+011$ & 0.5404 \\
\hline
\end{tabular}


The Robustness CCD and MCCD to one missing design point

The Robustness of CCD and MCCD to one missing design point of factorial, axial or center point using design efficiencies (A-efficiency)

Table 3.6 CCD Efficiency Values

\begin{tabular}{llll}
\hline Design type & design points N & Det & rA-eff \\
\hline Full & 31 & $2.2613 \mathrm{e}+012$ & \\
Factorial & 30 & $1.5202 \mathrm{e}+012$ & 0.9685 \\
Axial & 30 & $1.7105 \mathrm{e}+012$ & 0.9759 \\
Axial & 30 & $9.9294 \mathrm{e}+011$ & 0.9208 \\
Center & 30 & $2.0874 \mathrm{e}+012$ & $1.0000^{*}$ \\
\hline
\end{tabular}

Table 3.7: MCCD Efficiency Values

\begin{tabular}{llll}
\hline Design type & design points N & Det & rA-eff \\
\hline Full & 27 & $6.9578 \mathrm{e}+011$ & \\
Massing factorial & 26 & $4.3728 \mathrm{e}+011$ & 0.9428 \\
Missing axial & 26 & $2.9957 \mathrm{e}+011$ & 0.9063 \\
Missing Center & 26 & $6.1848 \mathrm{e}+011$ & $0.9671^{*}$ \\
\hline
\end{tabular}

The Robustness of CCD and MCCD to one missing design point of factorial, axial or center point using loss criteria (A-efficiency)

Table 3.8: Losses in relative efficiency for CCD

\begin{tabular}{lll}
\hline Design type & design points N & Loss A-eff \\
\hline Full & 31 & \\
Factorial & 30 & 0.0315 \\
Axial & 30 & 0.0241 \\
Axial & 30 & 0.0792 \\
Center & 30 & $0.0000^{*}$ \\
\hline
\end{tabular}

Table 3.9: Losses in Relative Efficiency for MCCD

\begin{tabular}{lll}
\hline Design type & design points N & Loss A-opt \\
\hline Full & 27 & \\
Massing factorial & 26 & 0.0572 \\
Missing axial & 26 & 0.0937 \\
Missing Center & 26 & $0.0329 *$ \\
\hline
\end{tabular}


Table 3.10 Model Terms CCD Real life data

\begin{tabular}{lllll}
\hline Term & Standard Error* & VIF & $\mathbf{R}_{\mathbf{i}}^{2}$ & Power \\
\hline A & 0.2041 & 1 & 0.0000 & $99.7 \%$ \\
B & 0.2041 & 1 & 0.0000 & $99.7 \%$ \\
C & 0.2041 & 1 & 0.0000 & $99.7 \%$ \\
D & 0.2041 & 1 & 0.0000 & $99.7 \%$ \\
AB & 0.2500 & 1 & 0.0000 & $96.9 \%$ \\
AC & 0.2500 & 1 & 0.0000 & $96.9 \%$ \\
$\mathrm{~B}^{2}$ & 0.1851 & 1.00775 & 0.0077 & $99.9 \%$ \\
\hline
\end{tabular}

Table 3.11 Model Terms MCCD real life data

\begin{tabular}{crrrr}
\hline \multicolumn{1}{l}{ Term Standard Error* } & \multicolumn{1}{l}{ VIF } & \multicolumn{1}{l}{$\mathbf{R}_{\mathbf{i}}{ }^{2}$} & \multicolumn{1}{l}{ Power } \\
\hline $\mathrm{A}$ & 0.2500 & 1 & 0.0000 & $96.6 \%$ \\
$\mathrm{~B}$ & 0.2041 & 1 & 0.0000 & $99.6 \%$ \\
$\mathrm{C}$ & 0.2041 & 1 & 0.0000 & $99.6 \%$ \\
$\mathrm{D}$ & 0.2500 & 1 & 0.0000 & $96.6 \%$ \\
$\mathrm{AB}$ & 0.2500 & 1 & 0.0000 & $96.6 \%$ \\
$\mathrm{AC}$ & 0.2500 & 1 & 0.0000 & $96.6 \%$ \\
$\mathrm{~B}^{2}$ & 0.1976 & 1.04167 & 0.0400 & $99.9 \%$ \\
$\mathrm{C}^{2}$ & 0.1976 & 1.04167 & 0.0400 & $99.9 \%$ \\
\hline
\end{tabular}

\section{DISCUSSIONS}

The work started with the finding a suitable non-standard model using the raw data on table 3.2 , notice that the data has three response variables but this work concentrated its effort on the first response variable with its output as $O, g / \mathrm{cm}^{3}$. First, a regression equation was set up using the output from minitab via the backward elimination strategy and the model of equation 3.1 was generated.

Now equation 3.1 is a classical nine parameters non-standard model which has some interaction and quadratic terms removed. The generated non-standard model of equation 3.1 was tested to ascertain that the model parameters are statistically significant and that the model is balanced using the standard error, VIF, and adjusted R-square in table 3.10 and 3.11 respectively.

Table 3.3 gives the A-optimality values of the CCD and MCCD when the designs are complete and the values of the A-optimal designs shows that the MCCD at this point is the most Aoptimal design compared to the CCD.

Table 3.4 and table 3.5 presents the A-optimality values when the CCD and MCD have a missing observation at the factorial, axial and center points respectively. The results also show that the MCCD is the most A-optimal. 
Table 3.6 and table 3.7 present the relative efficiency of the CCD and MCCD in the presence of a missing observation and the result shows that the CCD is most efficient at the various factor levels.

The losses incurred by the designs (CCD and MCCD) are presented on table 3.8 and table 3.9 shows that the loss at the center point is the lowest and is the minimum of the maximum loss (minimax loss) of the respective designs. Comparatively the CCD has a lower Minimax Loss compared to the MCCD, this shows that the CCD is more robust than the MCCD.

\section{CONCLUSION}

The model employed in this work is a balanced model as indicated by the available statistics. Comparatively the Modified Central Composite Design based on the available statistics is more A-optimal, but the CCD is more robust to a missing observation than the MCCD.

\section{REFERENCES}

Ahmed, L. A. (2016) Missing values estimation in split-plot design, international journal of computer and information technology, vol. 05

Akhtar M, Prescott P. (1986). Response surface designs robust to missing observations. Commun Stat Simul Comput. 1986;15:345-363.

Akram M. (2002), Central composite designs robust to three missing observations. Pakistan: The Islamia University of Bahawalpur; Doctoral Thesis.

Alrweili, H, Georgiou, S, and Stylianou, S. robustness of response surface designs to missing data, Qual Reliab Engng Int. 2019;35:1288-1296.

Box, GEP. and Hunter, JS. 1957. Multi-factor experimental designs for exploring response surfaces, Annals of Mathematical Statistics. 28:195-241.

Das, MN. and Narasimham, VL. (1962) Construction of rotatable designs through balanced incomplete block designs, Annals of Mathematical Statistics. 33: 1421-1439.

Gremyr, I. (2005). Robust Design Methodology - A Framework and Supportive Methods. Chalmers University of Technology. Gothenburg. Doctoral Thesis.

Iwundu, M. P. (2017) Missing observations: the loss in relative A-, D-, and G-efficiency. International journal of advanced mathematical sciences,5(2) 43-49

Smucker, B. J., Jesen, W., Wu, Z., and Wang, B. Robustness of classical and optimal designs to missing observations, Computational statistics and data analysis. 113

Subramani, J. (2004) Estimation of several missing values in experimental designs, research gate

Taguchi, G., S. Chowdhury and S. Taguchi (2000). Robust Engineering, McGraw-Hill, USA. ISBN 0-07-134782-8

Wallin, J. (2009) Conceptual Design for Robustness, Luleå University of Technology, MASTER'S THESIS 
$\mathrm{Wu}, \mathrm{D}$. and $\mathrm{Li}, \mathrm{Y} .(2002)$. Effects of the impregnating and drying process factors on the mechanical properties of a $\mathrm{PCOMo} / \mathrm{Al}_{2} \mathrm{O}_{3}$ hydrotreating catalyst. Elsevier science B.V pg101-109

Yakubu, Y., Chukwu, A. U., Adebayo, B. T., and Nwanzo G., Effects of missing observations on predictive capability of central composite designs, International journal on computer sciences and applications (IJCSA) Vol4, No 6. 